\title{
Evidence That Diffusion Limitation Determines Oxygen Uptake Kinetics during Exercise in Humans
}

Akira Koike, Kariman Wasserman, David K. McKenzie, Stefania Zanconato, and Daniel Weiler-Ravell

Division of Respiratory and Critical Care Physiology and Medicine, Harbor-UCLA Medical Center, Torrance, California 90509

\begin{abstract}
To determine the role of arterial $\mathrm{O}_{2}$ content on the mechanism of muscle $\mathrm{O}_{2}$ utilization, we studied the effect of 2,11 , and $20 \%$ carboxyhemoglobin (COHb) on $\mathrm{O}_{2}$ uptake $\left(\mathrm{V}_{2}\right)$, and $\mathrm{CO}_{2}$ output $\left(\dot{\mathrm{V}} \mathrm{CO}_{2}\right)$ kinetics in response to $6 \mathrm{~min}$ of constant moderate- and heavy-intensity cycle exercise in 10 subjects. Increased $\mathrm{COHb}$ did not affect resting heart rate, $\dot{\mathrm{V}} \mathrm{O}_{2}$ or $\dot{\mathrm{V}} \mathrm{CO}_{2}$. Also, the $\mathrm{COHb}$ did not affect the asymptotic $\mathrm{VO}_{2}$ in response to exercise. However, $\dot{\mathrm{V}} \mathrm{O}_{2}$ and $\dot{\mathrm{V}} \mathrm{CO}_{2}$ kinetics were affected differently. The time constant (TC) of $\dot{\mathrm{V}} \mathrm{O}_{2}$ significantly increased with increased $\mathrm{COHb}$ for both moderate and heavy work intensities. $\mathrm{VO}_{2} \mathrm{TC}$ was positively correlated with blood lactate. In contrast, $\dot{\mathrm{V}} \mathrm{CO}_{2} \mathrm{TC}$ was negatively correlated with increased COHb for the moderate but unchanged for the heavy work intensity. The gas exchange ratio reflected a smaller increase in $\mathrm{CO}_{2}$ stores and faster $\dot{\mathrm{V}} \mathrm{CO}_{2}$ kinetics relative to $\dot{\mathrm{V}} \mathrm{O}_{2}$ with increased $\mathrm{COHb}$. These changes can be explained by compensatory cardiac output (heart rate) increase in response to reduced arterial $\mathrm{O}_{2}$ content. The selective slowing of $\mathrm{VO}_{2}$ kinetics, with decreased blood $\mathrm{O}_{2}$ content and increased cardiac output, suggests that $\mathrm{O}_{2}$ is diffusion limited at the levels of exercise studied. (J. Clin. Invest. 1990. 86:1698-1706.) Key words: anaerobic threshold • carbon monoxide • carboxyhemoglobin • heart rate kinetics • lactate
\end{abstract}

\section{Introduction}

$\mathrm{O}_{2}$ uptake $\left(\dot{\mathrm{VO}}_{2}\right)^{1}$ by the lungs reflects $\dot{\mathrm{V}}_{2}$ by the muscles. The $\dot{\mathrm{V}}_{2}$ differs from the $\mathrm{O}_{2}$ requirement only when the $\mathrm{O}_{2}$ delivery to the muscles is inadequate to maintain an $\mathrm{O}_{2}$ partial pressure $\left(\mathrm{PO}_{2}\right)$ difference between muscle capillaries and muscle mitochondria to meet the immediate bioenergetic $\mathrm{O}_{2}$ requirement. Whereas a primary determinant of $\dot{\mathrm{VO}}_{2}$ kinetics in response to exercise must be muscle bioenergetics (1), the ade-

This study was presented in part at the 74th Annual Meeting of Federation of American Societies for Experimental Biology (FASEB), Washington, DC, April 1990.

Address reprint requests to Dr. Wasserman, Division of Respiratory and Critical Care Physiology and Medicine, A-15 Annex, Harbor-UCLA Medical Center, 1000 West Carson Street, Torrance, CA 90509.

Received for publication 19 January 1990 and in revised form 25 June 1990.

1. Abbreviations used in this paper: $\mathrm{COHb}$, carboxyhemoglobin; $\dot{\mathrm{v}} \mathrm{CO}_{2}, \mathrm{CO}_{2}$ output; $\dot{\mathrm{V}} \mathrm{O}_{2}, \mathrm{O}_{2}$ uptake.

J. Clin. Invest.

(c) The American Society for Clinical Investigation, Inc. 0021-9738/90/11/1698/09 \$2.00

Volume 86, November 1990, 1698-1706 quacy of the $\mathrm{O}_{2}$ supply to the muscles must also determine the kinetics. Reducing the arterial $\mathrm{O}_{2}$ content, without changing arterial $\mathrm{PO}_{2}$ and without an anticipatory increase in blood flow, would result in a more rapid rate of fall in capillary $\mathrm{PO}_{2}$ than normal. This would affect the pattern of $\mathrm{VO}_{2}$ by the muscles, only if $\mathrm{O}_{2}$ transport from muscle capillaries to mitochondria was diffusion limited.

Inhaling low concentrations of carbon monoxide (2-5) can affect $\mathrm{O}_{2}$ content of the arterial blood without affecting the diffusion equilibrium between $\mathrm{O}_{2}$ in the alveolar gas and the pulmonary capillary blood. At the tissue level, capillary $\mathrm{PO}_{2}$ would fall more rapidly than normal because of the reduced blood $\mathrm{O}_{2}$ content and the leftward shift of the oxyhemoglobin dissociation curve caused by the increased carboxyhemoglobin $(\mathrm{COHb})(6)$. The partial pressure of carbon monoxide (PCO) required to increase $\mathrm{COHb}$ to $20 \%(\sim 0.15 \mathrm{~mm} \mathrm{Hg})$ does not significantly affect oxymyoglobin (binding of carbon monoxide to myoglobin is only $10 \%$ of that to hemoglobin) and mitochondrial cytochromes (7). Any increase in blood flow caused by the reduced arterial $\mathrm{O}_{2}$ content would be compensatory and incomplete, resulting in a reduced mean and end capillary $\mathrm{PO}_{2}(4)$, and therefore reduced $\mathrm{O}_{2}$ availability to the exercising muscles. Thus if $\mathrm{O}_{2}$ uptake by the muscle mitochondria were limited by diffusion, rather than muscle bioenergetics alone, $\mathrm{VO}_{2}$ kinetics in response to a given work rate will be slowed when capillary $\mathrm{PO}_{2}$ was decreased. In order to determine the role of diffusion in $\mathrm{O}_{2}$ utilization during exercise, we measured $\dot{\mathrm{V}} \mathrm{O}_{2}, \mathrm{CO}_{2}$ output $\left(\mathrm{VCO}_{2}\right)$ and heart rate kinetics and end-exercise lactate while $\mathrm{COHb}$ was systematically controlled at $11 \%$ (level of heavy cigarette smoker) and $20 \%$, during constant work rate exercise.

\section{Methods}

Subjects. 10 normal nonsmoking subjects without cardiac or pulmonary disease ranging in age from 18 to $45 \mathrm{yr}$ were studied (Table I). The nature and purpose of the study and the risks involved were explained. Each subject voluntarily consented to participate in the study. The protocol and procedures for this study were reviewed and approved by the Institution's Human Subjects Committee.

Carbon monoxide loading. Carbon monoxide loading was accomplished using a procedure modified from Vogel and Gleser (4). This technique involved establishing a titration curve by monitoring venous $\mathrm{COHb}$ levels after breathing successive levels of 5-10 liters of $1 \%$ carbon monoxide in air using a co-oximeter (Instrument Laboratory, Inc., Lexington, MA) to measure $\mathrm{COHb}$. This titration was used to estimate the volume of $1 \%$ carbon monoxide that the subject needed to breathe in order to achieve $11 \%$ or $20 \% \mathrm{COHb}$ levels on the study days. No subject experienced symptoms from breathing the gas, and resting heart rate and minute ventilation were not changed.

Exercise protocol. Exercise tests were employed using an upright, electromagnetically braked cycle ergometer (Gould Godhart BV, Bilthaven, The Netherlands). Each subject performed two levels of exercise during three sessions on different days in randomized order as follows: one session without added carbon monoxide (control), one 
Table I. Physical Characteristics and Work Rates of Moderate and Heavy Intensity Studied for Each Subject

\begin{tabular}{|c|c|c|c|c|c|c|}
\hline \multirow[b]{2}{*}{ Subject } & \multirow[b]{2}{*}{ Age } & \multirow[b]{2}{*}{ Sex } & \multirow[b]{2}{*}{ Height } & \multirow[b]{2}{*}{ Weight } & \multicolumn{2}{|c|}{ Work } \\
\hline & & & & & Moderate & Heavy \\
\hline & $y r$ & & $\mathrm{~cm}$ & $k g$ & \multicolumn{2}{|c|}{$\boldsymbol{W}$} \\
\hline 1 & 45 & $\mathbf{M}$ & 180 & 79 & 120 & 200 \\
\hline 2 & 31 & $\mathbf{M}$ & 168 & 59 & 55 & 110 \\
\hline 3 & 40 & $\mathbf{M}$ & 168 & 70 & 50 & 110 \\
\hline 4 & 32 & $\mathbf{M}$ & 175 & 67 & 145 & 260 \\
\hline 5 & 29 & $\mathbf{F}$ & 168 & 60 & 100 & 200 \\
\hline 6 & 39 & $\mathbf{M}$ & 168 & 71 & 60 & 130 \\
\hline 7 & 31 & $\mathbf{M}$ & 186 & 86 & 130 & 260 \\
\hline 8 & 18 & $\mathbf{M}$ & 165 & 62 & 80 & 190 \\
\hline 9 & 28 & $\mathbf{M}$ & 175 & 69 & 80 & 200 \\
\hline 10 & 35 & $\mathbf{M}$ & 173 & 74 & 90 & 205 \\
\hline Mean \pm SD & $32.8 \pm 7.1$ & & $172.6 \pm 6.2$ & $69.7 \pm 8.1$ & $91.0 \pm 30.9$ & $186.5 \pm 51.6$ \\
\hline
\end{tabular}

session with $\sim 11 \% \mathrm{COHb}$, one session with $\sim 20 \% \mathrm{COHb}$. During each session, moderate and heavy work intensity exercise of 6 min each starting from rest were performed. Three repetitions of both moderate and heavy work intensity exercise were completed during each session whenever possible. The subjects rested at least $30 \mathrm{~min}$ between repetitions. The moderate and heavy work intensity exercise levels were determined by finding the work rates during air breathing corresponding to the $\mathrm{VO}_{2}$ at $80 \%$ of the anaerobic threshold (moderate exercise intensity), and the work rate at a $\dot{\mathrm{VO}}_{2}$ which was $40 \%$ of the difference between the anaerobic threshold and maximal ${ }_{\mathrm{V}} \mathrm{O}_{2}$ (heavy exercise intensity). The actual work rates performed at the moderate and heavy work intensities for each subject are shown in Table I. The anaerobic threshold and maximal $\dot{\mathrm{VO}}_{2}$ were previously determined for each subject from an incremental cycle ergometer exercise test while breathing room air without added carbon monoxide. The same protocol was used for all three levels of $\mathrm{COHb}$.

To obviate the energetic effect of inertia during acceleration of the flywheel at the start of exercise, an electric motor was used to drive the flywheel at $60 \mathrm{rpm}$ during the rest periods. The motor was switched off when the subject began pedaling. The start of exercise was signaled by the change of a light from red to green within the subject's view. To avoid startle responses, no verbal command was given.

To maintain the $\mathrm{COHb}$ at the $11 \%$ or $20 \%$ level, subjects breathed $0.023 \%$ carbon monoxide in air during exercise.

Measurements. Heart rate was continuously monitored by a cardiotachometer, and superficial forearm vein blood was obtained before and $2 \mathrm{~min}$ after the exercise for measurement of lactate (enzymatic method [8]). $\mathrm{COHb}$ level was also measured before and at the end of exercise.

Subjects breathed through a mouthpiece attached to a turbine volume transducer (Alpha Technologies, Hayward, CA) for measurements of ventilatory volumes during the test. Dead space of the system was $170 \mathrm{ml}$. Respired gases were sampled continuously from a site at the mouthpiece for analysis of $\mathrm{O}_{2}, \mathrm{CO}_{2}$, and $\mathrm{N}_{2}$ by mass spectrometry (Perkin-Elmer Corp., Norwalk, CT). Breath-by-breath calculations of alveolar $\dot{\mathrm{VO}}_{2}$ and $\dot{\mathrm{V}} \mathrm{CO}_{2}$ were performed as previously described (9).

Data analysis. To enhance the signal to noise ratio, three repetitions of each test were performed and superimposed for both moderate and heavy work intensity exercise in six subjects. Two repetitions were performed and superimposed for only moderate work intensity exercise in two subjects. For the remaining two subjects with less noisy breathing, a single transition of each test was performed and analyzed. The repetitions were more important for low work rate exercise in subjects with noisy breathing.
The breath-by-breath data from each of the three repetitions for each 6-min test were interpolated to give values second by second. These values were time-aligned to a mark at the start of exercise, and superimposed to average random noise and enhance the underlying response patterns for each test with each $\mathrm{COHb}$ level for each subject (10). These averaged 60 responses (two work rates, three $\mathrm{COHb}$ levels, and 10 subjects) were then used for data analysis. $\mathrm{O}_{2}$ pulse was calculated every second by dividing $\dot{\mathrm{V}}_{2}$ by heart rate.

To determine the kinetics of $\dot{\mathrm{V}}_{2}$, the time constant was determined for all the data from the start of exercise, assuming exponential kinetics, using least square nonlinear regression through the data. The asymptotic $\mathrm{V}_{2}$ was determined by fitting the data to the sum of two exponentials, as previously described by Linnarsson (11). The first exponential term described the kinetics to $180 \mathrm{~s}$ and the second exponential term described the kinetics for the data between 180 and $360 \mathrm{~s}$. The overall dynamics were then expressed as a single exponential time constant through all the data from the resting $\mathrm{VO}_{2}$ to the asymptotic $\dot{\mathrm{V}} \mathrm{O}_{2}$, when $\dot{\mathrm{VO}}_{2}$ did not reach steady state by $6 \mathrm{~min}$, or actual steadystate $\dot{\mathrm{VO}}_{2}$ if steady state was established before $6 \mathrm{~min}$. The same analysis was used for $\dot{\mathrm{V}} \mathrm{CO}_{2}$, heart rate, and $\mathrm{O}_{2}$ pulse. While $\dot{\mathrm{VO}}_{2}$ kinetics may be more complex than a single exponential increase for heavy exercise (12-14), this approach is a useful model, as previously reported (15).

The increase in $\mathrm{V}_{2}$ at 6 min as compared to 3 min of constant work rate tests $\left[\Delta \dot{\mathrm{VO}}_{2}(6-3)\right]$, a measurement which was described by Roston et al. (16) to be highly correlated with the increase in blood lactate, was also calculated.

$\mathrm{COHb}$ levels for a given test were determined from the average of the values before and after the test.

Statistical methods. Differences in the parameters without added carbon monoxide (control), with 11\% $\mathrm{COHb}$ and $20 \% \mathrm{COHb}$ were determined by analysis of variance for repeated measures. When the $F$ test was significant, individual comparisons were made by NewmanKeuls' multiple-range test. Variations about the mean are expressed as \pm 1 SD and differences were considered significant at the $P<0.05$ level.

\section{Results}

The physical characteristics of the subjects are shown in Table I. Venous lactate concentration at rest before exercise averaged $1.0 \pm 0.4 \mathrm{mM} /$ liter for control studies, $1.2 \pm 0.5 \mathrm{mM} /$ liter for $11 \% \mathrm{COHb}$ studies, and $1.2 \pm 0.7 \mathrm{mM} /$ liter for $20 \% \mathrm{COHb}$ studies. The differences were not significant. 
Table II. COHb Level of Each Exercise Test

\begin{tabular}{|c|c|c|c|c|c|c|}
\hline \multirow[b]{2}{*}{ Subject } & \multicolumn{3}{|c|}{ Moderate intensity tests } & \multicolumn{3}{|c|}{ Heavy intensity tests } \\
\hline & Control & $11 \% \mathrm{COHb}$ & $20 \% \mathrm{COHb}$ & Control & $11 \% \mathrm{COHb}$ & $19 \% \mathrm{COHb}$ \\
\hline 1 & 2.0 & 13.5 & 19.6 & 2.0 & 13.7 & 18.5 \\
\hline 2 & 2.5 & 11.3 & 19.4 & 2.5 & 12.6 & 19.4 \\
\hline 3 & 2.5 & 11.4 & 19.4 & 2.5 & 11.8 & 19.7 \\
\hline 4 & 2.0 & 11.6 & 21.2 & 2.0 & 11.8 & 20.2 \\
\hline 5 & 1.1 & 12.4 & 20.5 & 1.1 & 11.2 & 19.3 \\
\hline 6 & 3.0 & 12.1 & 19.0 & 3.0 & 13.1 & 18.9 \\
\hline 7 & 0.8 & 9.6 & 20.1 & 0.8 & 9.7 & 18.6 \\
\hline 8 & 0.9 & 10.2 & 23.3 & 0.7 & 10.7 & 20.4 \\
\hline 9 & 0.8 & 9.2 & 21.6 & 0.8 & 10.0 & 19.4 \\
\hline 10 & 0.6 & 11.3 & 19.4 & 0.6 & 11.1 & 17.8 \\
\hline Mean \pm SD & $1.6 \pm 0.8$ & $11.2 \pm 1.2$ & $20.3 \pm 1.3$ & $1.6 \pm 0.9$ & $11.5 \pm 1.2$ & $19.2 \pm 0.7$ \\
\hline
\end{tabular}

The mean $\mathrm{COHb}$ level of each test during exercise is given in Table II. The actual $\mathrm{COHb}$ level without added carbon monoxide (control tests), and with added carbon monoxide during exercise were $1.6 \pm 0.8 \%, 11.2 \pm 1.2 \%$, and $20.3 \pm 1.3 \%$, for the moderate work intensity tests, and $1.6 \pm 0.9 \%$, $11.5 \pm 1.2 \%$, and $19.2 \pm 0.7 \%$ for heavy work intensity tests, respectively. These increased $\mathrm{COHb}$ levels were kept almost constant during exercise by breathing $0.023 \%$ carbon monoxide.

Superficial forearm venous lactate concentration of the control (air breathing) study obtained 2 min after the moder- ate work intensity exercise was $1.1 \pm 0.6 \mathrm{mM} /$ liter and increased to a small but significant amount at the $20 \% \mathrm{COHb}$ level (Table III, Fig. 1). For the heavy work intensity exercise, lactate concentration was $5.0 \pm 2.0 \mathrm{mM} / \mathrm{liter}$ for the control study and increased to $6.7 \pm 1.8$ and $9.4 \pm 1.1 \mathrm{mM} /$ liter, for the $11.5 \%$ and $19.2 \% \mathrm{COHb}$ levels, respectively. These increases were significant at each level of $\mathrm{COHb}$ (Table III, Fig. 1).

Fig. 2 shows the responses of $\mathrm{VO}_{2}, \dot{\mathrm{V}} \mathrm{CO}_{2}$, and gas exchange ratio in one representative subject (subject 4 in Table I) during both moderate and heavy work intensity tests without added carbon monoxide and with $\sim 20 \% \mathrm{COHb}$. The $\dot{\mathrm{VO}}_{2}$ of

Table III. $\dot{\mathrm{V}} \mathrm{O}_{2}, \dot{V} \mathrm{CO}_{2}$, Heart Rate, and $\mathrm{O}_{2}$-Pulse Responses to Moderate and Heavy Work Rate Tests and Lactate Concentration Obtained 2 min after Exercise

\begin{tabular}{|c|c|c|c|c|c|c|c|c|}
\hline & \multicolumn{4}{|c|}{ Moderate intensity tests } & \multicolumn{4}{|c|}{ Heavy intensity tests } \\
\hline & Control & $11 \% \mathrm{COHb}$ & $20 \% \mathrm{COHb}$ & $P$ value & Control & $11 \% \mathrm{COHb}$ & $19 \% \mathrm{COHb}$ & $P$ value \\
\hline Time constant of $\dot{\mathrm{VO}}_{2}(s)$ & 28.8 & 30.5 & 33.6 & $<0.0001$ & 51.4 & 59.5 & 67.5 & 0.0001 \\
\hline$\pm \mathrm{SD}$ & 4.1 & 5.5 & 5.5 & & 11.7 & 12.8 & 16.5 & \\
\hline $\mathrm{V}_{2}$ at $6 \mathrm{~min}($ liter $/ \mathrm{min})$ & 1.69 & 1.70 & 1.71 & NS & 2.88 & 2.90 & 2.87 & NS \\
\hline$\pm \mathrm{SD}$ & 0.37 & 0.38 & 0.39 & & 0.67 & 0.67 & 0.60 & \\
\hline$\dot{\mathrm{V}}_{2}$ asymptote (liter/min) & 1.71 & 1.69 & 1.74 & NS & 2.95 & 3.00 & 2.97 & NS \\
\hline$\pm \mathrm{SD}$ & 0.36 & 0.38 & 0.40 & & 0.67 & 0.68 & 0.61 & \\
\hline$\Delta \dot{\mathrm{V}}_{2}(6-3)($ liter/min) & 0.030 & 0.036 & 0.041 & NS & 0.145 & 0.209 & 0.265 & 0.003 \\
\hline$\pm \mathrm{SD}$ & 0.047 & 0.045 & 0.062 & & 0.051 & 0.073 & 0.089 & \\
\hline Time constant of $\dot{\mathrm{V} C O_{2}}(s)$ & 68.3 & 57.5 & 53.9 & 0.007 & 70.0 & 73.1 & 75.4 & NS \\
\hline$\pm \mathrm{SD}$ & 10.2 & 12.6 & 12.8 & & 17.5 & 15.9 & 22.4 & \\
\hline$\dot{\mathrm{v}} \mathrm{CO}_{2}$ asymptote (liter/min) & 1.54 & 1.51 & 1.57 & NS & 2.81 & 2.98 & 3.07 & $<0.02$ \\
\hline$\pm \mathrm{SD}$ & 0.35 & 0.36 & 0.36 & & 0.65 & 0.64 & 0.59 & \\
\hline HR asymptote (beats/min) & 115.0 & 118.9 & 131.7 & $<0.0001$ & 157.4 & 166.6 & 173.6 & 0.0002 \\
\hline$\pm \mathrm{SD}$ & 8.3 & 12.8 & 11.4 & & 6.8 & 5.1 & 10.6 & \\
\hline $\mathrm{O}_{2}$-pulse asymptote $(\mathrm{ml} /$ beat $)$ & 14.8 & 14.0 & 13.1 & $<0.0001$ & 18.9 & 18.0 & 16.9 & 0.0002 \\
\hline$\pm \mathrm{SD}$ & 2.8 & 3.1 & 2.6 & & 3.9 & 4.1 & 3.4 & \\
\hline Lactate $(m M /$ liter $)$ & 1.1 & 1.5 & 1.9 & $<0.02$ & 5.0 & 6.7 & 9.4 & $<0.0001$ \\
\hline$+\mathrm{SD}$ & 0.6 & 0.8 & 0.6 & & 2.0 & 1.8 & 1.1 & \\
\hline
\end{tabular}

$\Delta \dot{\mathrm{VO}}_{2}(6-3)=$ the increase in $\mathrm{O}_{2}$ uptake at $6 \mathrm{~min}$ as compared to $3 \mathrm{~min}$ of constant work rate tests. $P$ value was determined by analysis of variance for repeated measures. $\mathrm{HR}$, heart rate. 
MODERATE WORK

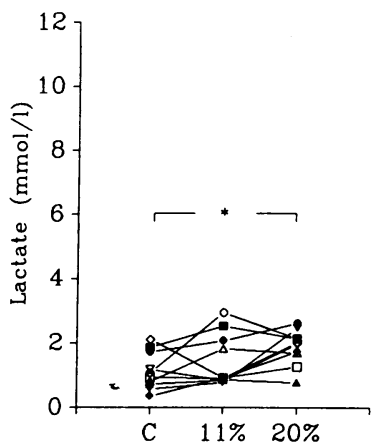

HEAVY WORK

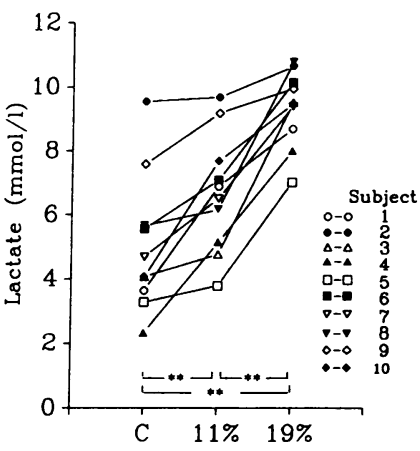

Figure 1. Venous lactate concentration of each test obtained 2 min after exercise. The symbols for each subject are indicated on the figure, and the subject numbers correspond to those in Tables I and II ${ }^{*} P<0.05,{ }^{* *} P<0.01$ by Newman-Keuls' multiple-range test. $\mathrm{C}$, control studies; $11 \%$, studies with $11.2 \% \mathrm{COHb}$ for moderate work intensity and $11.5 \% \mathrm{COHb}$ for heavy work intensity exercise; $19 \%$, studies with $19.2 \% \mathrm{COHb}$; $20 \%$, studies with $20.3 \% \mathrm{COHb}$. For moderate-intensity exercise, the two levels of $\mathrm{COHb}$ averaged $11.2 \%$ and $20.3 \%$. For heavy work intensity exercise, the two levels of $\mathrm{COHb}$ averaged $11.5 \%$ and $19.2 \%$.

the moderate work intensity test of the control study reached a steady state within $\sim 1 \mathrm{~min}$ and remained constant until the end of exercise.
Mean $\mathrm{VO}_{2}$ at 6 min of the control, $11 \%$ and $20 \% \mathrm{COHb}$ test were $1.69 \pm 0.37,1.70 \pm 0.38$, and $1.71 \pm 0.39 \mathrm{liter} / \mathrm{min}$ for the moderate work intensity tests and $2.88 \pm 0.67,2.90 \pm 0.67$, and $2.87 \pm 0.60 \mathrm{liter} / \mathrm{min}$ for the heavy work intensity tests, respectively (Table III). There was no difference in $\mathrm{VO}_{2}$ at 6 $\mathrm{min}$ as related to $\mathrm{COHb}$ level. For both moderate and heavy work intensity tests, the $\mathrm{VO}_{2}$ asymptote, calculated by a single exponential curve fit to the $\dot{\mathrm{V}} \mathrm{O}_{2}$ response, did not change with increased $\mathrm{COHb}$ levels (Table III). However, the time constant for $\dot{\mathrm{VO}}_{2}$ kinetics were significantly increased with increased $\mathrm{COHb}$ levels (Fig. 3). The time constants of the heavy work intensity tests were higher than those of the moderate work intensity tests, and increased to a greater degree with increased COHb levels (Fig. 3).

Fig. 4 shows the relationship between the time constant of $\mathrm{VO}_{2}$ and the lactate concentration. The time constant of $\dot{\mathrm{VO}}_{2}$ increased with the level of lactate, showing a strong statistical correlation $(r=0.869, P<0.0001)$.

Fig. 5 shows $\Delta \dot{\mathrm{V}} \mathrm{O}_{2}(6-3)$ of each test. Although there was no significant difference in $\Delta \mathrm{V}_{2}$ (6-3) for moderate work intensity tests, $\Delta \mathrm{VO}_{2}(6-3)$ of heavy work intensity tests significantly increased with increased $\mathrm{COHb}$. Despite the fact that the time constant is dominated by data during the first $3 \mathrm{~min}$ of testing, whereas $\Delta \dot{\mathrm{V}} \mathrm{O}_{2}(6-3)$ is determined by data between 3 and 6 min of exercise, $\Delta \dot{\mathrm{V}} \mathrm{O}_{2}(6-3)$ correlated well with lactate concentration ( $r=0.784, P<0.0001$ ) (Fig. 6).

The $\mathrm{VCO}_{2}$ asymptote did not change for moderate work

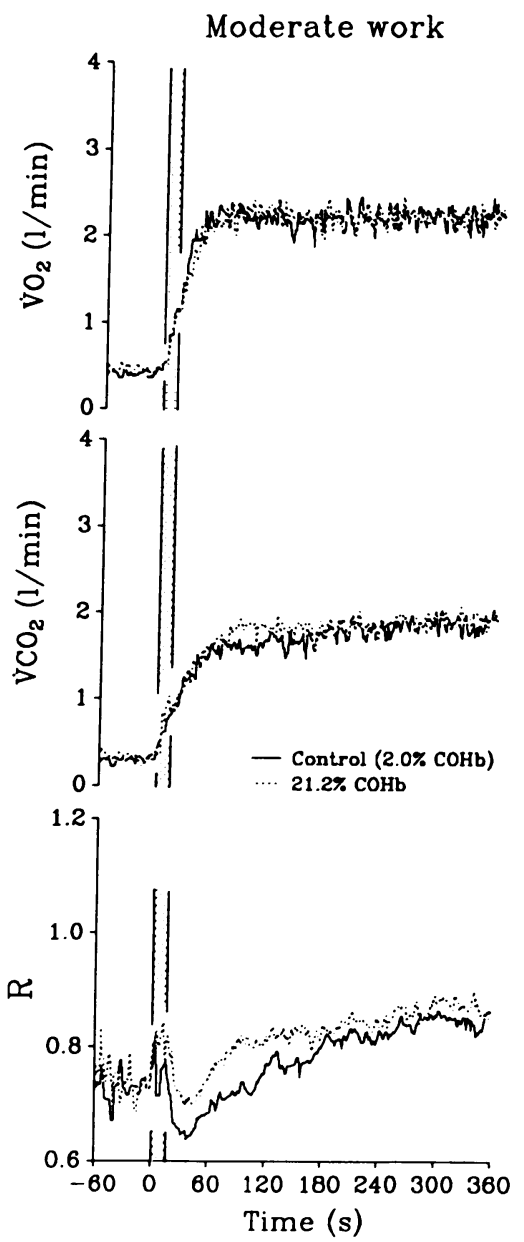

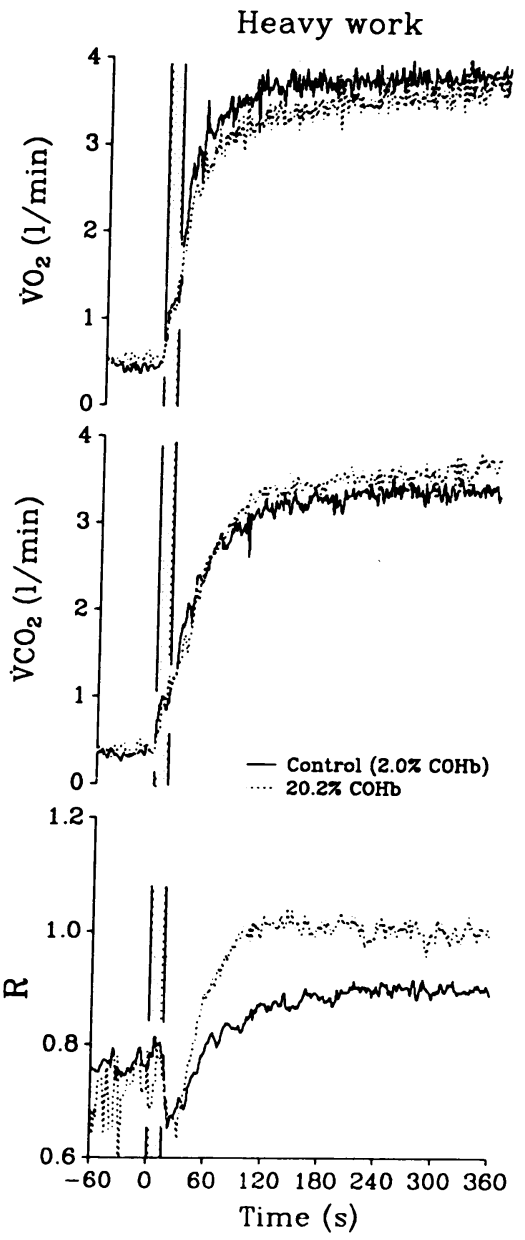

Figure 2. Effects of increased $\mathrm{COHb}$ on $\mathrm{V}_{2}$, $\dot{\mathrm{V}} \mathrm{CO}_{2}$, and gas exchange ratio (R) during moderate $(145 \mathrm{~W})$ and heavy $(260 \mathrm{~W})$ work intensity exercise without added carbon monoxide and with $\sim 20 \% \mathrm{COHb}$ in one subject (subject 4 in Table I). The values to the left of time " 0 " are measured at rest. The shaded area denotes cardiodynamic phase (15 s after the onset of exercise). 
MODERATE WORK

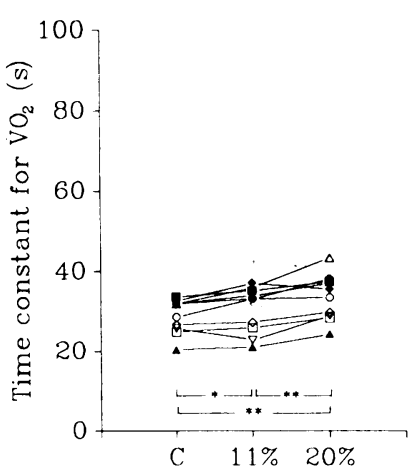

HEAVY WORK

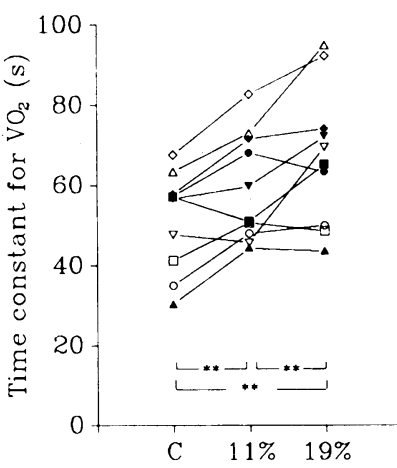

Figure 3. The time constant of $\mathrm{V}_{2}$ in response to moderate and heavy work intensity exercise for 10 subjects. Time constant of $\dot{\mathrm{VO}}_{2}$ for both moderate and heavy work intensity tests was significantly increased with increased $\mathrm{COHb}$ levels. ${ }^{*} P<0.05,{ }^{* *} P<0.01$ by Newman-Keuls' multiple-range test. C, control studies; $11 \%$, studies with $11.2 \% \mathrm{COHb}$ for moderate work intensity and $11.5 \% \mathrm{COHb}$ for heavy work intensity exercise; $19 \%$, studies with $19.2 \% \mathrm{COHb} ; 20 \%$, studies with $20.3 \%$ COHb.

intensity tests, but was significantly higher for the heavy work intensity $19 \% \mathrm{COHb}$ studies $(3.07 \pm 0.59 \mathrm{liter} / \mathrm{min})$ than the control studies $(2.81 \pm 0.65 \mathrm{liter} / \mathrm{min})$ (Table III). The time constant of $\dot{\mathrm{VCO}}_{2}$ of the moderate work intensity tests was $68.3 \pm 10.2 \mathrm{~s}$ for the control study, $57.5 \pm 12.6 \mathrm{~s}$ for the $11 \%$ COHb study, and $53.9 \pm 12.8 \mathrm{~s}$ for the $20 \% \mathrm{COHb}$ study, showing a significant decrease with increased $\mathrm{COHb}$ levels $(P$ $<0.05$ between the control and $11 \% \mathrm{COHb}$ study, and $P$ $<0.01$ between the control and $20 \%$ COHb study) in contrast to the $\dot{\mathrm{V}} \mathrm{O}_{2}$ changes (Table III). There was no significant difference in the $\dot{\mathrm{V} C O}{ }_{2}$ time constant for heavy work intensity tests.

Fig. 7 relates the ratio of the $\dot{\mathrm{VCO}}_{2}$ and $\dot{\mathrm{VO}}_{2}$ time constants to blood lactate. The ratio, while averaging 2.4 for the air-

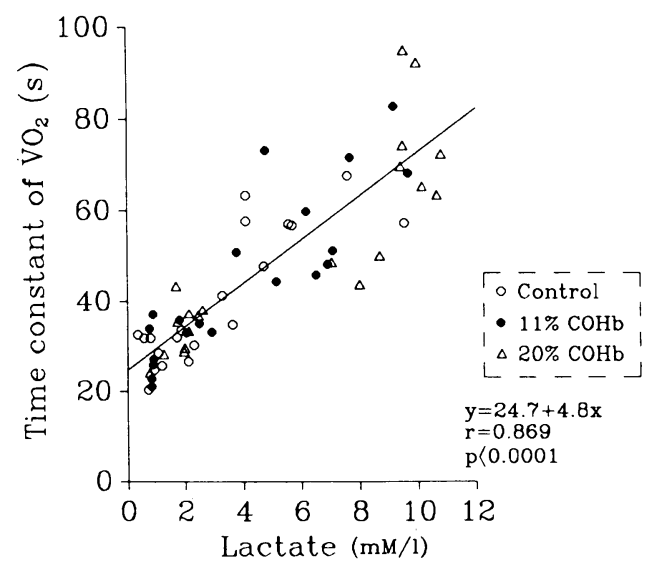

Figure 4. Relationship between the time constant of $\dot{\mathrm{VO}}_{2}$ and superficial forearm vein lactate concentration obtained 2 min after exercise. Data are for both moderate and heavy work intensity exercise at each $\mathrm{COHb}$ level; symbols for $20 \% \mathrm{COHb}$ studies in this figure include $20 \% \mathrm{COHb}$ studies of moderate work intensity exercise and $19 \% \mathrm{COHb}$ studies of heavy work intensity exercise.
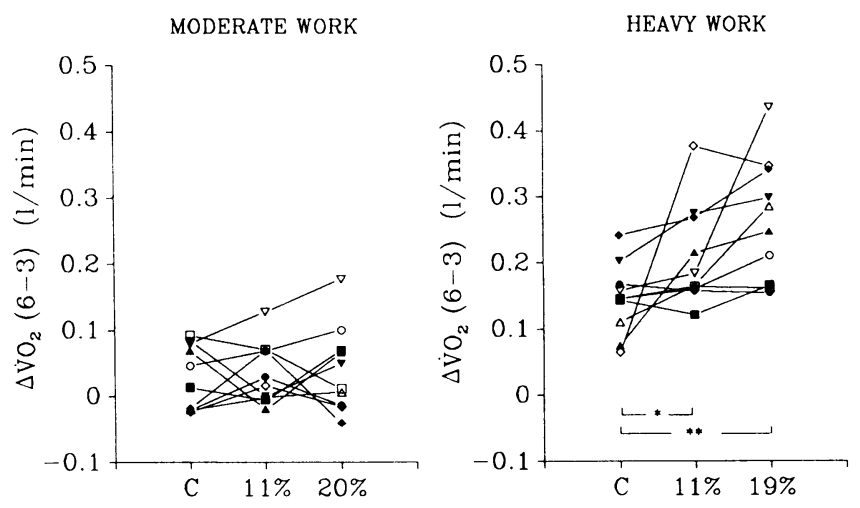

Figure 5. The increase in $\mathrm{O}_{2}$ uptake at $6 \mathrm{~min}$ as compared to $3 \mathrm{~min}$ of constant work rate tests $\left[\Delta \dot{\mathrm{VO}}_{2}(6-3)\right]$ for each test. $\Delta \dot{\mathrm{VO}} \mathrm{O}_{2}(6-3)$ of heavy work intensity tests significantly increased with increased COHb. ${ }^{*} P<0.05,{ }^{* *} P<0.01$ by Newman-Keuls' multiple-range test. C, control studies; $11 \%$, studies with $11.2 \% \mathrm{COHb}$ for moderate work intensity and $11.5 \% \mathrm{COHb}$ for heavy work intensity exercise; $19 \%$, studies with $19.2 \% \mathrm{COHb} ; 20 \%$, studies with $20.3 \% \mathrm{COHb}$.

breathing moderate work intensity tests, decreased strikingly and approached 1 as lactate increased. This ratio significantly decreased with increased $\mathrm{COHb}$ for both moderate and heavy work intensity exercise, as well as between moderate and heavy exercise at each $\mathrm{COHb}$ level. This decrease was primarily due to slowed $\dot{\mathrm{VO}}_{2}$ kinetics with faster or unchanged $\dot{\mathrm{VCO}}_{2}$ kinetics.

Fig. 8 shows heart rate responses during both moderate and heavy work intensity exercise in one subject (the same subject as shown in Fig. 2). There was no difference in heart rate at rest but the rate of rise and peak heart rate response was greater the higher the $\mathrm{COHb}$ level for both moderate and heavy work intensity. The asymptotic values were significantly increased with increased $\mathrm{COHb}$ for the group as a whole (Table III).

Fig. 9 shows the kinetics of $\mathrm{O}_{2}$ pulse during moderate and heavy work intensity exercise tests in one subject (the same subject as shown in Fig. 2). Peak values are seen by $1 \mathrm{~min}$ for

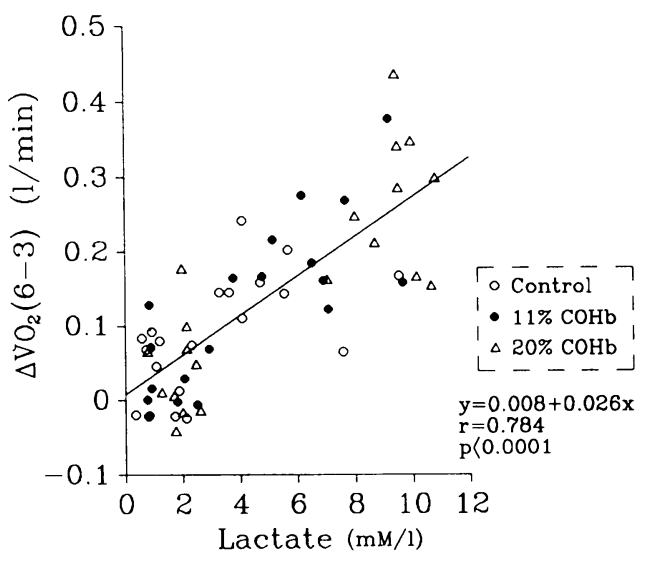

Figure 6. Relationship between the increase in $\mathrm{O}_{2}$ uptake at $6 \mathrm{~min}$ as compared to $3 \mathrm{~min}$ of constant work rate tests $\left[\Delta \mathrm{V}_{2}(6-3)\right]$ and superficial forearm vein lactate concentration obtained 2 min after exercise. Symbols are same as those noted in Fig. 4. 


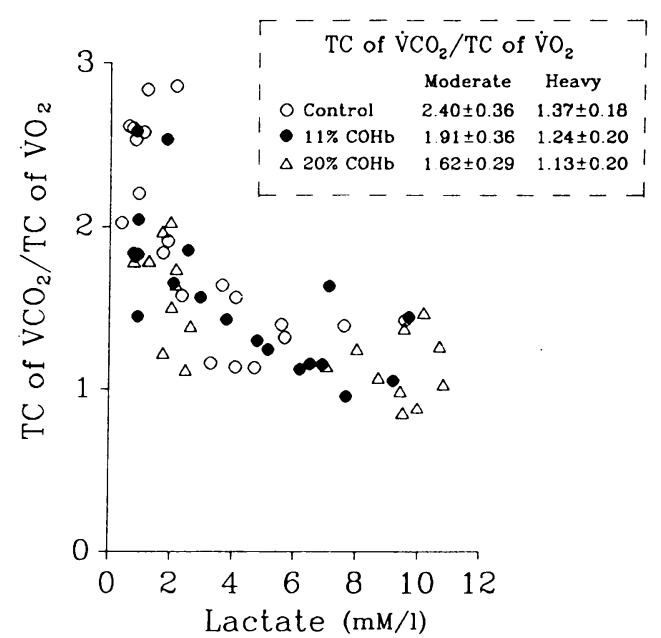

Figure 7. Relationship between the ratio of the time constant (TC) of $\dot{\mathrm{V}} \mathrm{CO}_{2}$ and that of $\dot{\mathrm{VO}}_{2}$ and forearm vein lactate concentration obtained 2 min after exercise. Each symbol includes the data of both moderate and heavy work intensity exercise of each $\mathrm{COHb}$ level, as described in Fig. 4. The inset relates TC of $\mathrm{VCO}_{2} / \mathrm{TC}$ of $\dot{\mathrm{VO}}_{2}$ to the intensity of work rate and the $\mathrm{COHb}$ level.

the moderate work intensity. For the heavy work intensity with increased $\mathrm{COHb}, \mathrm{O}_{2}$ pulse increased further after the 1stmin increase. In all instances $\mathrm{O}_{2}$ pulse abruptly increased at the start of exercise and then oscillated for $15 \mathrm{~s}$ before increasing to its asymptote. The asymptotic values were significantly decreased with increased $\mathrm{COHb}$ for both work rate tests (Table III). Since $\mathrm{O}_{2}$ pulse is equal to stroke volume $\times$ arterial-venous $\mathrm{O}_{2}$ difference, and stroke volume is known not to change (4), the decrease likely reflects the expected reduction in arterialvenous $\mathrm{O}_{2}$ difference.

For both moderate and heavy work intensity tests, the gas exchange ratio decreased during the first minute, after a 15 -s delay (Fig. 2). The near-constant gas exchange ratio at resting levels during the first 15 s of exercise, before the gas exchange ratio decreases, is postulated to be due to the proportional increase in $\dot{\mathrm{V}} \mathrm{CO}_{2}$ and $\dot{\mathrm{V}} \mathrm{O}_{2}$ caused by increase in pulmonary blood flow at the start of exercise with the arterial-venous difference being that of the before-exercise resting state (17). The subsequent decrease in the gas exchange ratio is postulated to be due to arrival of blood at the lungs from exercising muscle. Because of $\mathrm{CO}_{2}$ solubility in tissues, part of the early metabolic $\mathrm{CO}_{2}$ is retained as tissue $\mathrm{PCO}_{2}$ increases consequent to the smaller increase in cardiac output relative to metabolic rate, i.e., increase in arterial-venous $\mathrm{O}_{2}$ difference is greater than increase in venous-arterial $\mathrm{CO}_{2}$ difference during this non-steady-state period.

With increased $\mathrm{COHb}$, the cardiac output response is increased, even for moderate intensity work, as evidenced by the increased heart rate response (Fig. 8 and Table III). This would result in a reduced arterial-venous $\mathrm{O}_{2}$ (lower $\mathrm{O}_{2}$ pulse, Fig. 9) and $\mathrm{CO}_{2}$ concentration difference and therefore less $\mathrm{CO}_{2}$ retention in the tissues. Thus $\mathrm{CO}_{2}$ output kinetics would be expected to be faster (approach that of $\mathrm{O}_{2}$ ) even for moderate work intensity exercise (Table III), and the decrease in the gas exchange ratio during the first minute would be expected to be attenuated as found in this study (Fig. 2).

\section{Discussion}

Constant work rate exercise does not require a subject's maximum effort if the work rate is not unreasonably high and if exercise duration is not too long. Using a constant work rate test, the patterns of $\dot{\mathrm{VO}} \mathrm{O}_{2}, \dot{\mathrm{V}} \mathrm{CO}_{2}$, heart rate, and $\mathrm{O}_{2}$-pulse increase in response to an exercise stimulus can be quantified and be used as descriptors of cardiopulmonary adaptations to exercise $(10,18-21)$. The binding of hemoglobin by carbon monoxide reversibly decreases the $\mathrm{O}_{2}$ carrying capacity, producing a useful model of the effect of a modest acute reduction in $\mathrm{O}_{2}$ transport. Thus this model was applied in this study to determine the sensitivity of $\dot{\mathrm{VO}}_{2}$ kinetics to detect small
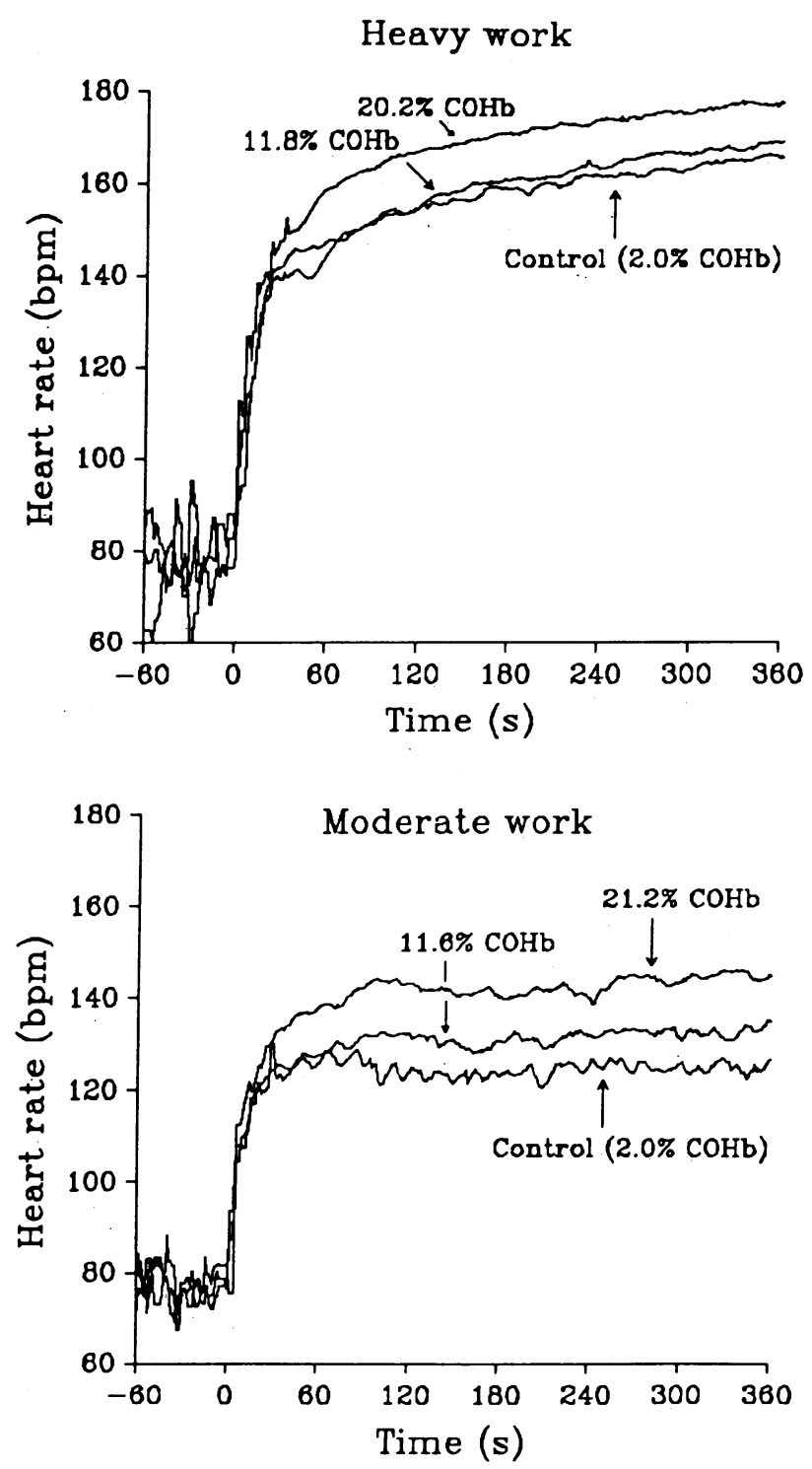

Figure 8. The effect of increased $\mathrm{COHb}$ on heart rate response during moderate $(145 \mathrm{~W})$ and heavy $(260 \mathrm{~W})$ work intensity exercise in one subject (subject 4 in Table I). There was no difference in heart rate at rest but the rate of rise and peak heart rate response during exercise was greater the higher the $\mathrm{COHb}$ level for both moderate and heavy work intensity. 

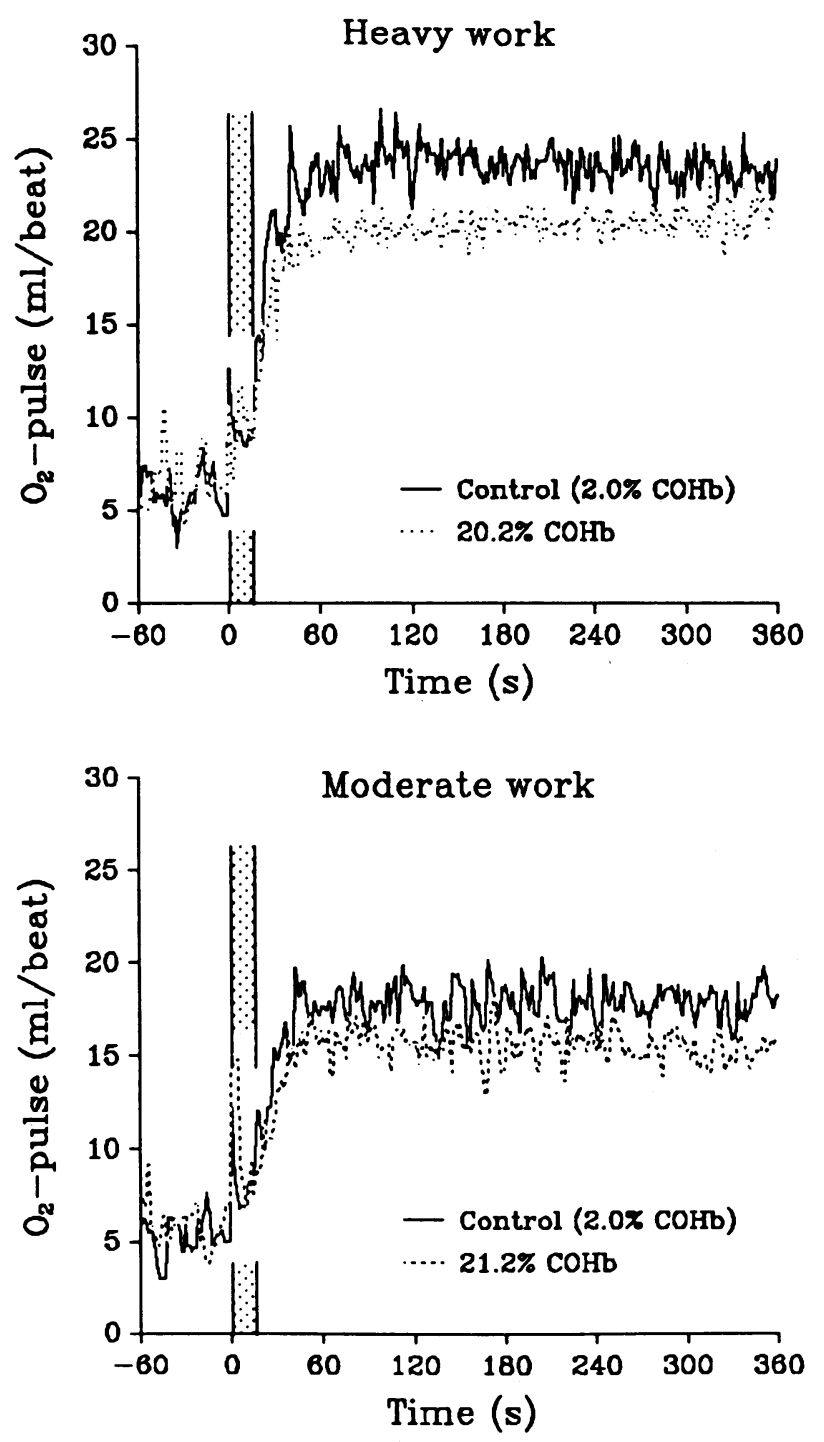

Figure 9. The effect of increased $\mathrm{COHb}$ on $\mathrm{O}_{2}$ pulse as related to time during moderate $(145 \mathrm{~W})$ and heavy $(260 \mathrm{~W})$ work intensity exercise without added carbon monoxide and with $\sim 20 \% \mathrm{COHb}$ in one subject (subject 4 in Table I). For the heavy work intensity with increased $\mathrm{COHb}, \mathrm{O}_{2}$ pulse increased slightly after the rapid rise within the 1 st min.

changes in arterial $\mathrm{O}_{2}$ content and transport without a change in $\mathrm{PO}_{2}$.

Carbon monoxide has the effect of reducing $\mathrm{O}_{2}$ content and shifting the oxyhemoglobin dissociation curve to the left requiring a lower capillary $\mathrm{PO}_{2}$ for $\mathrm{O}_{2}$ unloading from hemoglobin. It has been described by Root (22) that the concentration to which $\mathrm{COHb}$ can be increased, which is compatible with life, does not poison the cells of the body. While there are only limited studies on the level of Pco that starts to affect resting cell redox state or electron transport, it appears to be considerably higher than that required to raise $\mathrm{COHb}$ to $20 \%$ according to the studies of Wittenberg and Wittenberg (7) on cardiac myocytes and our lactate measurements.

To maintain the level of $\mathrm{COHb}$ during exercise, our subjects breathed a concentration of $0.023 \%$ carbon monoxide in air. During the moderate and heavy intensity exercise the $\mathrm{COHb}$ slightly increased for the $11 \% \mathrm{COHb}(11.0 \pm 1.2$ to $11.8 \pm 1.4 \%$ ) and was unchanged or decreased for the $20 \%$ COHb level study $(19.9 \pm 1.5$ to $19.6 \pm 1.3 \%)$. Thus the blood and therefore tissue PCO must have been in the range of 0.1-0.2 $\mathrm{mmHg}$, in agreement with the predicted PCO for 11 and $20 \% \mathrm{COHb}$ from the $\mathrm{COHb}$ dissociation curve in air (6). This is well below the PCO that has a demonstrable effect on oxymyoglobin (affinity of carbon monoxide to myoglobin is only $10 \%$ of that to hemoglobin) and levels of PCO that affect the mitochondrial cytochromes (7). Further evidence that the low levels of PCO used in this study did not cause tissue toxicity is that $\mathrm{VO}_{2}$ and ventilation (sensitive markers of acid-base balance and cell redox state) at rest were not affected. Also, resting lactate concentration was not affected by these levels of PCO. Furthermore, we found no difference in the 6-min $\mathrm{VO}_{2}$ and $\mathrm{VO}_{2}$ asymptote for both moderate and heavy work intensity tests as related to $\mathrm{COHb}$ level.

It had been reported that the time constant of $\mathrm{VO}_{2}$ is prolonged in patients with obstructive pulmonary disease (19) and patients with heart disease (10) compared with normal subjects. It had also been reported by Hughson and Smyth (20) and Petersen et al. (23) that beta-blockade slows the $\mathrm{V}_{2}$ increase during submaximal exercise in normal subjects. In contrast to the latter studies, which slowed $\mathrm{VO}_{2}$ kinetics by attenuating the cardiac output increase, this study slowed $\mathrm{VO}_{2}$ kinetics by effectively reducing capillary $\mathrm{PO}_{2}$. Heart rate (cardiac output) was increased (Fig. 8), presumably as compensation for the impaired $\mathrm{O}_{2}$ delivery.

In this study, the time constant for $\dot{\mathrm{V}}_{2}$ significantly increased with increasing levels of $\mathrm{COHb}$ (Fig. 3), even if the work intensity was moderate and lactate concentration was $<2 \mathrm{mM} /$ liter at the end of exercise. Since the heart rate increase suggests that cardiac output is actually increased under these circumstances (4), slowing of $\mathrm{VO}_{2}$ kinetics must be attributed to the reduced blood $\mathrm{O}_{2}$ content and capillary-mitochondrial $\mathrm{PO}_{2}$ difference. For higher-intensity work, the effect of reducing $\mathrm{O}_{2}$ content by increased $\mathrm{COHb}$ was more marked (Fig. 3) and $\mathrm{VO}_{2}$ kinetics were slower, the higher the blood lactate (Fig. 4). These studies show that both lactate concentration and the time constant for $\mathrm{VO}_{2}$ are increased in response to a relatively small reduction in $\mathrm{O}_{2}$ transport.

$\dot{\mathrm{VO}}_{2}$ continues to increase slowly beyond $3 \mathrm{~min}$ at work rates associated with increased blood lactate $(16,24)$. Roston et al. (16) measured the increase in $\mathrm{VO}_{2}$ at 6 min as compared to $3 \mathrm{~min}$ [ $\Delta \dot{\mathrm{VO}}_{2}(6-3)$ ], during constant work rate exercise of different intensities in normal men and showed a good correlation with the increase in blood lactate. In this study, we also showed a good correlation between $\Delta \dot{\mathrm{VO}}_{2}(6-3)$ and lactate concentration (Fig. 6).

At rest, gas exchange at the lungs is equal to gas exchange at the cells. Thus, the gas exchange ratio at rest reflects the metabolic respiratory quotient that is determined by the mixture of substrate used for energy $(24,25)$. After the onset of exercise, the immediate increase in pulmonary blood flow (resulting from increased heart rate and stroke volume) causes an abrupt increase in both $\dot{\mathrm{V}} \mathrm{O}_{2}$ and $\dot{\mathrm{V}} \mathrm{CO}_{2}$ (25), during which the gas exchange ratio changes little for the first $15 \mathrm{~s}$ (Fig. 2) (17). The gas exchange ratio then decreases, i.e., $\mathrm{VCO}_{2}$ rise lags the increase in $\dot{\mathrm{VO}} 2$, because $\mathrm{CO}_{2}$ is more soluble in tissues and 
blood than $\mathrm{O}_{2}$. Thus the time constant of $\mathrm{VCO}_{2}$ is longer than that of $\mathrm{VO}_{2}$ for work rates below the anaerobic threshold (19, 24-27). However, at work rates accompanying lactic acidosis (Fig. 7), the rate of increase in $\mathrm{VCO}_{2}$ approaches and sometimes exceeds that of $\mathrm{VO}_{2}$ as the latter slows and the former remains the same or becomes faster. Additional $\mathrm{CO}_{2}$ generated from $\mathrm{HCO}_{3}^{-}$, as it buffers the increase in lactic acid, is undoubtedly responsible for the disparate changes in $\mathrm{VCO}_{2}$ and $\dot{\mathrm{VO}}_{2}$ kinetics observed in this study. Consistent with these findings, Springer et al. $(28,29)$ observed slowing of $\mathrm{VO}_{2}$ kinetics and speeding of $\dot{\mathrm{V}} \mathrm{CO}_{2}$ kinetics in response to hypoxia.

Although heart rate at rest did not differ for different $\mathrm{COHb}$ levels, heart rate during exercise became significantly higher with increased $\mathrm{COHb}$ levels. This is presumably due to a compensatory stimulation of heart rate to maintain adequate $\mathrm{O}_{2}$ delivery to the working muscles when blood $\mathrm{O}_{2}$ content is reduced. Increasing the cardiac output relative to metabolic rate, without a reduction in $\mathrm{O}_{2}$ content, should increase capillary $\mathrm{PO}_{2}$. The increase in cardiac output (heart rate) (Fig. 8), and the rightward shift in the oxyhemoglobin dissociation curve consequent to increased lactic acidosis, are apparently the mechanisms by which it was possible for $\mathrm{VO}_{2}$ to increase to the same steady state (moderate intensity) or 6 -min $\dot{\mathrm{V}}_{2}$ (heavy intensity) in the control and increased $\mathrm{COHb}$ studies.

$\mathrm{O}_{2}$ pulse, which did not differ at rest, significantly decreased during both moderate and heavy work intensity exercise with increased $\mathrm{COHb}$ levels (Fig. 9). As $\mathrm{O}_{2}$ pulse is mathematically equal to the product of stroke volume and the arterial-venous $\mathrm{O}_{2}$ difference, decreased $\mathrm{O}_{2}$ content of the arterial blood and decreased arterial-venous $\mathrm{O}_{2}$ difference must be responsible for the decreased $\mathrm{O}_{2}$ pulse during exercise observed with increased $\mathrm{COHb}$. This is similar to the effect of anemia.

Fick's law of diffusion states that the mass transfer $(D)$ of a substance, such as $\mathrm{O}_{2}$, is directly proportional to the partial pressure difference between the high pressure point in the capillary $(P c)$ to the low pressure point in the mitochondria $(P m)$ and the surface area $(A)$ (degree of capillary hyperemia), and inversely related to the diffusion distance $(L)$ (capillary to mitochondria), that is, $D \mathrm{O}_{2}=k(P c-P m) * A / L$. The proportionality constant $(k)$ is a function of the diffusibility and solubility of $\mathrm{O}_{2}$ in the tissue substance.

Increasing the $\mathrm{COHb}$ should have no effect on arterial $\mathrm{PO}_{2}$ $(4,30)$. However, as with anemia (31), the capillary and venous $\mathrm{PO}_{2}$ should be decreased at submaximal work rates (4) since the increase in blood flow is compensatory and does not completely adjust for the reduced $\mathrm{O}_{2}$ flow caused by the increased $\mathrm{COHb}$. Increased $\mathrm{COHb}$ also results in a further lowering of capillary $\mathrm{PO}_{2}$ because it causes leftward shift in the oxyhemoglobin dissociation curve. Whereas the effect of the increased $\mathrm{COHb}$ is to reduce the capillary to mitochondrial $\mathrm{PO}_{2}$ difference, any increase in capillary surface area resulting from increased blood flow, would facilitate diffusion. Also, capillary recruitment with increased blood flow should reduce diffusion distance and speed $\dot{\mathrm{VO}}_{2}$ kinetics.

In this study, we experimentally reduced the capillary-mitochondrial $\mathrm{O}_{2}$ diffusion gradient without affecting the steadystate or asymptotic $\mathrm{V}_{2}$ and thus presumably mitochondrial function. We conclude that the slowing of $\dot{\mathrm{VO}}_{2}$ kinetics found in this study is most likely explained by diffusion limited $\mathrm{O}_{2}$ transport to the contracting muscle mitochondria at moderate as well as heavy work intensities.

\section{Acknowledgments}

This work was supported by U. S. Public Health Service grant HL-1 1907. Akira Koike was supported by funds from Otsuka Pharmaceutical Co. and Merrell Dow Pharmaceuticals K.K.

\section{References}

1. Whipp, B. J.; and M. Mahler. 1980. Dynamics of pulmonary gas exchange during exercise. In Pulmonary Gas Exchange. J. West, editor. Academic Press, Inc., New York. 33-96.

2. Pirnay, F., J. Dujardin, R. Deroanne, and J. M. Petit. 1971. Muscular exercise during intoxication by carbon monoxide. J. Appl. Physiol. 31:573-575.

3. Ekblom, B., and R. Huot. 1972. Response to submaximal and maximal exercise at different levels of carboxyhemoglobin. Acta Physiol. Scand. 86:474-482.

4. Vogel, J. A., and M. A. Gleser. 1972. Effect of carbon monoxide on oxygen transport during exercise. J. Appl. Physiol. 32:234-239.

5. Raven, P. B., B. L. Drinkwater, R. O. Ruhling, N. Bolduan, S. Taguchi, J. Gliner, and S. M. Horvath. 1974. Effect of carbon monoxide and peroxyacetyl nitrate on man's maximal aerobic capacity. $J$. Appl. Physiol. 36:288-293.

6. Roughton, F. J. W. 1964. Transport of oxygen and carbon monoxide. In Handb. Physiol. (Sect. 3 Respir.) 1:767-825.

7. Wittenberg, B. A., and J. B. Wittenberg. 1987. Myoglobin-mediated oxygen delivery to mitochondria of isolated cardiac myocytes. Proc. Natl. Acad. Sci. USA. 84:7503-7507.

8. Olsen, C. 1971. An enzymatic fluorimetric micromethod for the determination of acetoacetate, beta-hydroxybutyrate, pyruvate and lactate. Clin. Chim. Acta. 33:293-300.

9. Beaver, W. L., N. Lamarra, and K. Wasserman. 1981. Breathby-breath measurement of true alveolar gas exchange. J. Appl. Physiol. 51:1662-1675.

10. Sietsema, K. E., D. M. Cooper, J. K. Perloff, M. H. Rosove, J. S. Child, M. M. Canobbio, B. J. Whipp, and K. Wasserman. 1986. Dynamics of oxygen uptake during exercise in adults with cyanotic congenital heart disease. Circulation. 73:1137-1144.

11. Linnarsson, D. 1974. Dynamics of pulmonary gas exchange and heart rate changes at start and end of exercise. Acta Physiol. Scand. Suppl. 415:1-68.

12. Whipp, B. J., and K. Wasserman. 1972. Oxygen uptake kinetics for various intensities of constant-load work. J. Appl. Physiol. 33:351356.

13. Hagberg, J. M., J. P. Mullin, and F. J. Nagle. 1978. Oxygen consumption during constant-load exercise. J. Appl. Physiol. 45:381384.

14. Camus, G., G. Atchou, J. C. Bruckner, D. Giezendanner, and P. E. Di Prampero. 1988. Slow upward drift of $\dot{\mathrm{V}}_{2}$ during constantload cycling in untrained subjects. Eur. J. Appl. Physiol. 58:197-202.

15. Sietsema, K. E., J. A. Daly, and K. Wasserman. 1989. Early dynamics of $\mathrm{O}_{2}$ uptake and heart rate as affected by exercise work rate. J. Appl. Physiol. 67:2535-2541.

16. Roston, W. L., B. J. Whipp, J. A. Davis, D. A. Cunningham, R. M. Effros, and K. Wasserman. 1987. Oxygen uptake kinetics and lactate concentration during exercise in humans. Am. Rev. Respir. Dis. 135:1080-1084.

17. Wasserman, K. 1988. New concepts in assessing cardiovascular function. Circulation. 78:1060-1071.

18. Karlsson, H., B. Lindborg, and D. Linnarsson. 1975. Time courses of pulmonary gas exchange and heart rate changes in supine exercise. Acta Physiol. Scand. 95:329-340.

19. Nery, L. E., K. Wasserman, J. D. Andrews, D. J. Huntsman, J. E. Hansen, and B. J. Whipp. 1982. Ventilatory and gas exchange kinetics during exercise in chronic airways obstruction. J. Appl. Physiol. 53:1594-1602.

20. Hughson, R. L., and G. A. Smyth. 1983. Slower adaptation of 
$\dot{\mathrm{VO}}_{2}$ to steady state of submaximal exercise with beta-blockade. Eur. $J$. Appl. Physiol. 52:107-110.

21. Casaburi, R., S. Spitzer, R. Haskell, and K. Wasserman. 1989. Effect of altering heart rate on oxygen uptake at exercise onset. Chest. 95:6-12.

22. Root, W. S. 1965. Carbon monoxide. Handb. Physiol. 1087-1098.

23. Petersen, E. S., B. J. Whipp, J. A. Davis, D. J. Huntsman, H. V. Brown, and K. Wasserman. 1983. Effects of beta-adrenergic blockade on ventilation and gas exchange during exercise in humans. J. Appl. Physiol. 54:1306-1313.

24. Wasserman, K., J. E. Hansen, D. Y. Sue, and B. J. Whipp. 1987. Principles of Exercise Testing and Interpretation. Lea \& Febiger, Philadelphia. 6-20.

25. Wasserman, K. 1984. Coupling of external to internal respiration. Am. Rev. Respir. Dis. 129(Suppl.):S21-S24.

26. Cerretelli, P., R. Sikand, and L. E. Farhi. 1966. Readjustments in cardiac output and gas exchange during onset of exercise and recovery. J. Appl. Physiol. 21:1345-1350.

27. Diamond, L. B., R. Casaburi, K. Wasserman, and B. J. Whipp. 1977. Kinetics of gas exchange and ventilation in transitions from rest or prior exercise. J. Appl. Physiol. 43:704-708.

28. Springer, C., T. J. Barstow, K. Wasserman, and D. M. Cooper. 1990. Oxygen uptake and heart rate responses during hypoxic exercise in children and adults. Med. Sci. Sports Exercise. In press.

29. Springer, C., T. J. Barstow, and D. M. Cooper. 1989. Effect of hypoxia on ventilatory control during exercise in children and adults. Pediatr. Res. 25:285-290.

30. Ekblom, B., R. Huot, E. M. Stein, and A. T. Thorstensson. 1975. Effect of changes in arterial oxygen content on circulation and physical performance. J. Appl. Physiol. 39:71-75.

31. Woodson, R. D., R. E. Wills, and C. Lenfant. 1978. Effect of acute and established anemia on $\mathrm{O}_{2}$ transport at rest, submaximal and maximal work. J. Appl. Physiol. 44:36-43. 